Research Paper

\title{
Learn Idioms Using Augmented Reality
}

\section{Nur Amalia Atikah Edyanto ${ }^{1}$, Siti Zalifah Ramli ${ }^{1}$, Nur Ain Najihah Ibharim ${ }^{1}$, Siti Aishah Zahari $^{1}$, Muhammad Asyraf Abdullah Zawawi ${ }^{2}$}

${ }^{1}$ Program of Software Engineering, Department of Computing, Faculty of Art, Computing \& Creative Industry. Sultan Idris Education University, Malaysia.

${ }^{2}$ Program of Information Technology (Education), Department of Computing, Faculty of Art, Computing \& Creative Industry. Sultan Idris Education University, Malaysia.

\section{Article History}

Received:

28.02.2021

Revised:

12.03.2021

Accepted:

14.03.2021

*Corresponding Author: Nur Amalia Atikah Edyanto Email:

amalia@gmail.com

This is an open access article, licensed under: $\mathrm{CC}-\mathrm{BY}-\mathrm{SA}$
Abstract: English language is international language that are worldwide use and also one of the important language in communication and a main-medium of instruction in education in Malaysia. In order to become good in English we must learn since we were kids like since preschool and primary school and that show how important to learn English language. Then it need to help the students especially the pre-school and the primary school students to learn English in more effective and attractive ways so that they will not feel boring or lost interest in learning English language. Aim of this research is to find an interactive tool that can be used in learning an English idioms. This research use RAD Model to develop AR application and quantitative methods through questionnaires were implemented to evaluate the research that were developed. The research was evaluated by 10 teachers who teach English Language and evaluated based on usefulness, satisfaction and ease of use questionnaires.

Keywords: Augmented Reality, Educational Technology, Idioms, Multimedia. 


\section{Introduction}

Nowadays, English language has become one of the important language in communication and also become a main medium of instruction in education in Malaysia [1]. Moreover, we are living in the era of internet and technology, the use of English language has increased massively [2]. So that means English language has become one of the language that we need to know and need to be learn since we were young just like we learn how to speak our national language which is bahasa melayu that we learn since we were a baby, since we can say our first word.

As we know, our country Malaysia, a country of south-east asia has been using English in daily life since malaysia was colonized by british, this happen because in that era many of English-medium school was established on that time in Penang, Singapore and Malacca. So, many of our people went to the school for education and many of them use it in their daily life for example use English language to communicate with non-citizens people, traders and others. So, the use of English has become more widespread since then until now.

English language is international language that are worldwide use and also one of the important language in communication and a main-medium of instruction in education in Malaysia. So, to become good in English language, we need to learn it. To become good in English language mean by we can understand English, we can speak in English and we can write in English. In order to become good in English we must learn since we were kids like since preschool and primary school and that show how important to learn English language [2].

As we know, in human life we start to learn and discover since we were kids or even explore new things which that also one of the way to learn. In Malaysia the official education started since the kids was 4 years old. They start with going to the kindergarten, then after that going to the primary school, then going to the secondary school, diploma, degree and others. So from this order we know that everyone will get their education early since they were kids and we know kids can receive and store information.

The ministry of education in Malaysia already specified the syllabus for every stage for the students by publishing a textbook for the teachers and students as a references for, so that the teacher will know what they need to teach their students the right syllabus according to their ages and stages based on the textbook provided by the government and also the students can use their textbook as a references for their syllabus.

The aim of this research is to find interactive tool that can help the students especially the pre-school and the primary school students to learn English in more effective and attractive ways so that they will not feel boring or lost interest in learning English language and this application also more focusing on idioms since idioms are the things that the student hard to memorize and rarely used in their essay because they do not know which idioms are suitable, and sometime they cannot even memorize the idioms.

\section{Literature Review}

\subsection{Teaching and Learning tools}

Teaching and learning tools is a tools that help teachers to teach their students in more effective ways [3] [4]. This tools can be varies according to the need to make the learning process become more interesting and to avoid the learning process become so bored [5] [6] [7]. The tools is one of the alternative ways to learn that can be use besides textbook. It can be in a form of photos, videos, animations, artifacts and others to help the learning process. Nowadays, in this era of technology the education also become more advanced along with the technology. There were many technology that are created and developed for teaching and learning tools to improve the quality of education.

Hundreds of digitals education tools or teaching and learning tools have been created with the purpose of giving autonomy to the student, improving the administration of academic processes, facilitating communication and encouraging collaboration between teachers and students or learners. The example of the tools are:

- Edmodo

- Socrative

- ClassDojo

- Animoto

- Kahoot! 
Nur Amalia Atikah Edyanto, Siti Zalifah Ramli, Nur Ain Najihah Ibharim, Siti Aishah Zahari, Muhammad Asyraf Abdullah Zawawi

\subsection{Previous Existing System \\ 2.2.1. Instagram}

Instagram is one of the famous social media right now. This application allows you to post a picture about anything you want to post and share with everyone and also in this instagram also you can update what you are doing right now. In this application, you can follow the person that you think you want to follow or the person that you think important or follow the artist just to keep up-to-date what they are doing currently. Instagram can be used as a tool in education [8].

Instagram application also allows you to interact with other user by doing instagram live which and update you activities in instagram story. In instagram live and instagram story, there were many filter you can choose to use and many of the filters use augmented reality (AR) which is one of the reason why instagram become one of the previous existing system or application that can be used as a references or prototype for this project.

This application developed by Instagram, Inc. on 2010 for iOs and 2012 for Android. This application need 140.7 MB to download it on iOs devices and 31.43 MB for Android devices. Both of this application are free to download but both of this application provide in-app purchases. This application fall for photos and videos category and were ranking in number 2 for this category after Youtube on iOs and top one for social free category on Android.. This application required iOs 11.0 or latest for iOs devices and is compatible with iPhone, iPad and iPad touch. The main languages for the application is English and the application is for user above 12 years old.

The features in this application are:

- Add photos and videos to your insta story that disappear for 24 hours, and bring them to life with fun creative tools.

- Message your friends in direct messages and start the fun conversations with other user.

- Post photos or videos to your feed that you want to show on your profile

- Check out for the IGTV for longer videos from other user.

- Get inspired by photos and videos from new instagram account in Explore.

- Discover brands ans small businesses and shop products that are relevant to your style.

\subsection{Snapchat}

Snapchat is one of the famous social media platform that implement Augmented Reality (AR) in their application, and it can be used as a tool in teaching \& learning process [9]. Compared to instagram, this application mostly focusing about the picture or video that have been taken by user and user can edit it before post and share it to others user.

This application is developed by Snap, Inc. and is 194.3 MB to be downloaded for iOs devices and 49.99 MB for Android devices. The application is free but it have in-app purchase. This application fall for photo and video category on iOs and was ranked on top 10 in this category while in Android devices this application fall for social free category and was ranked on top 7 in this category. It requires iOs 10.0 or later and is compatible with only certain iPhone, iPad and iPad touch that are stated on the application description in the apple app store. The languages of the application used is English and the application is for user above 12 years old.

This application offers some features which are:

- Take a photo and record videos

- Add lens or filter to the photos and videos

- Create custom filters to add to the photos and videos

- Stay in touch and chat with friends with live messaging, or share your day with group stories.

- Video chat with up to 16 friends at once and even can use filters and lenses.

- Watch friends' stories

- Explore new things from top creator

- Watch breaking news and exclusive original shows.

- Enjoy a curated feed

- Share location with friends

\subsection{Augmented Reality}

Augmented Reality (AR) works when a virtual objects aaplied in real physical world where the virtual imagery in AR interfaces attached to real locations and objects and allow users to see like the real object. 
AR has been used as tool to help a techer and student in teaching \& learning process [10]. There are many example of AR application that is used in education field, for example, Rahani et al was using AR to learn Logic Gates [11], Abidin et al was using AR to learn Object Oriented Programming [12], Abu Samah was using AR to learn 3D Animation [13], Norhalim and Ismail was using AR to learn how to get healthy diet [14], and Giraldi et al was applied AR in engineering subjecr [15].

\section{Methodology}

This research is use the Rapid Application Development (RAD) model to develop the system. The critical feature of this RAD model is the use of powerful development tools and techniques. RAD model can be used if the project can be divided into small modules where each module can be assigned independently to separate teams [16].

The development of each module involves the basic steps for waterfall model which is analysing, designing, coding and testing. This model consists of four basic phases which are Requirements Planning, User Description, Construction and Implementation.

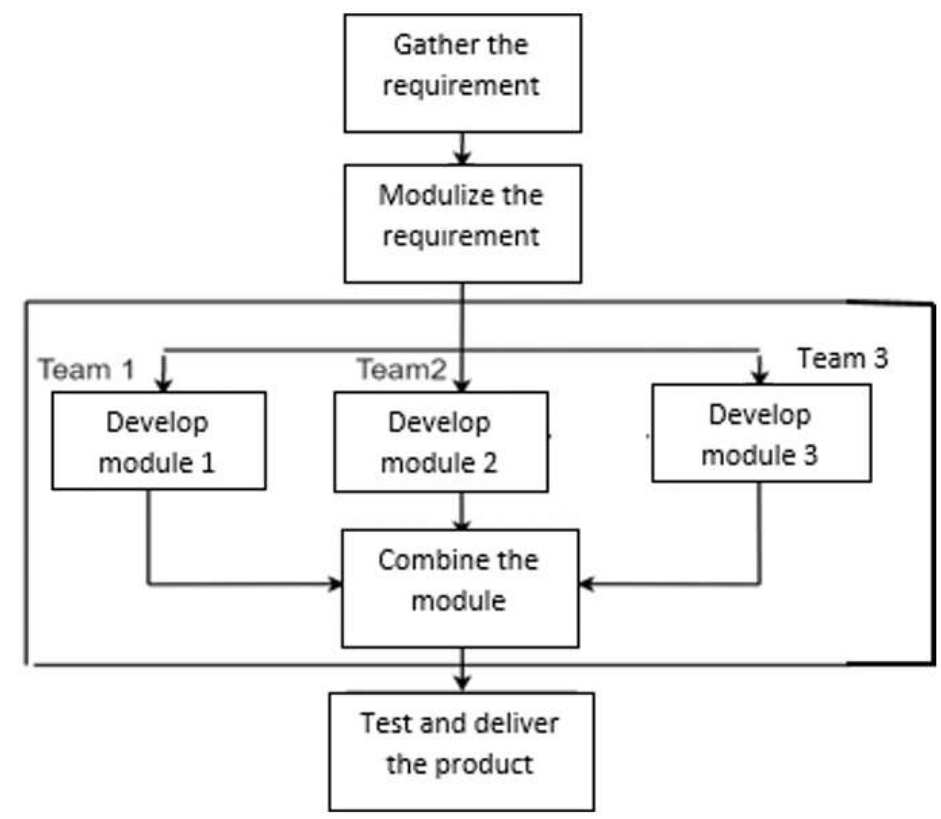

Figure 1. RAD Model

Table 1. Description for Phases in RAD Model

\begin{tabular}{ll}
\hline \multicolumn{1}{c}{ Phases } & \multicolumn{1}{c}{ Description } \\
\hline $\begin{array}{l}\text { Phase 1: } \\
\text { Analysis and } \\
\text { Design }\end{array}$ & $\begin{array}{l}\text { The activities in this phase are researching the current problems, } \\
\text { seeking the information and references, define and gather the } \\
\text { requirements andfinalize the requirements. }\end{array}$ \\
\hline $\begin{array}{l}\text { Phase 2: } \\
\text { User Design }\end{array}$ & $\begin{array}{l}\text { The activities in this phase is where the users can test each prototype } \\
\text { of the product, at each stage, to ensure it meets their expectations. }\end{array}$ \\
\hline $\begin{array}{l}\text { Phase 3: } \\
\text { Construction }\end{array}$ & $\begin{array}{l}\text { The activities in this phase are the refinement of the prototype } \\
\text { and delivery takes place. }\end{array}$ \\
\hline $\begin{array}{l}\text { Phase 4: } \\
\text { Implementation }\end{array}$ & $\begin{array}{l}\text { The activities in this phase are data conversion, testing, and } \\
\text { improvement or changes to the new system and the user training. }\end{array}$ \\
\hline
\end{tabular}


Nur Amalia Atikah Edyanto, Siti Zalifah Ramli, Nur Ain Najihah Ibharim, Siti Aishah Zahari, Muhammad Asyraf Abdullah Zawawi.

There were a few reasons why Rapid Application Development Model was chosen for this research are:

1. Rapid Application Development model enhanced the adaptability and the flexibility so that the developers can make adjustments or improvements directly and quickly during the development process. This action will minimize the errors and faults occured and can fulfil the clients or user's requirement and specification.

2. In addition, Rapid Application Development model includes integrations early in the software development process compared to the waterfall model which is an iterative model.

3. Rapid Application Development model can be use by the user and there will be a changes or improvements made from the user feedback to the prototype during the process before the final product is completed.

\section{Evaluation}

Performance tests will be carried out on users to see the effectiveness of using AR applications that are developed in increasing student interest and understanding of English idioms. The assessment uses a questionnaire technique that looks at various dimensions such as design, use, learning ability, satisfaction, and future application use. The questionnaire consists of five scales ranging from one to strongly disagree, followed by the next number in sequence and ending with a scale of five to strongly agree. To test the effectiveness and satisfaction level of the application, respondents will be given the opportunity to use.

\section{Conclusion}

This research was done with objectives to give interactive tool in learning an English idioms. RAD model used to develop the application and application evaluated by using quantitative questionnaires.

\section{References}

[1] N. H. Misbah, M. Mohamad, M. M. Yunus, and A. Ya'acob, "Identifying the Factors Contributing to Students' Difficulties in the English Language Learning," Creative Education, vol. 8, no. 13, pp. 1999-2008, January 2017.

[2] H. Mohd, "English language and the language of development: A Malaysian perspective," Jurnal Kemanusiaan, 2004.

[3] H. Halim, W. A. N. Wan Idris, H. Hassan, and I. Y. Panessai, "Learning Logic Gate through 7Gates," ijmari, vol. 2, no. 1, pp. 1-10, Mar. 2020.

[4] M. A. Ishak, M. R. Kosnan, and N. F. Zakaria, "Build IoT through Virtual Reality", ijmari, vol. 2, no. 1, pp. 11-25, Mar. 2020.

[5] W. A. N. Wan Idris, H. Halim, H. Hassan, and I. Y. Panessai, "GENIUS KIDS: Learn to Count through Games," International Journal of Multimedia and Recent Innovation, vol. 1, no. 1, pp. 1-17, Mar. 2020.

[6] Z. Zakaria, H. Hassan, H. Halim, W. A. N. Wan Idris, M. A. Zawawi, and N. F. Mansor, "Learning Mathematics: One Minute," International Journal of Multimedia and Recent Innovation, vol. 2, no. 2, pp. 76-86, Sep. 2020.

[7] S. F. Sezali, A. M. Radzuan, N. I. Mohd Shabudin, and R. A. Afendi, "POCKET MALAYSIA: Learning about States in Malaysia Using Augmented Reality", International Journal of Multimedia and Recent Innovation, vol. 2, no. 1, pp. 45-59, Mar. 2020.

[8] N. K. M. Douglas, M. Scholz, M. A. Myers, S. M. Rae, A. Elmansouri, S.Hall, and S. Border, "Reviewing the Role of Instagram in Education: Can a Photo Sharing Application Deliver Benefits to Medical and Dental Anatomy Education?" Medical Science Educator, vol. 29, pp. 1117-1128, 2019.

[9] AEDT - the Conversation, "How to use Snapchat in the laboratory for better student engagement," November 20, 2018. [Online]. Available: https://theconversation.com/how-to-usesnapchat-in-the-laboratory-for-better-student-engagement-105146. [Accessed: Sept. 2020].

[10] P. Chen, X. Liu, W. Cheng, and R. Huang, "A review of using Augmented Reality in Education from 2011 to 2016," Innovations in Smart Learning, Lecture Notes in Educational Technology, 2016. 
Nur Amalia Atikah Edyanto, Siti Zalifah Ramli, Nur Ain Najihah Ibharim, Siti Aishah Zahari, Muhammad Asyraf Abdullah Zawawi.

[11] N. H. Rahani, A. A. Bilong, M. R. Mat Suruji, and I. Y. Panessai, "Learning Logic Gates Using Augmented Reality", International Journal of Multimedia and Recent Innovation, vol. 2, no. 1, pp. 26-44, Mar. 2020.

[12] Z. Zainal Abidin and M. A. Abdullah Zawawi, "OOP-AR: Learn Object Oriented Programming Using Augmented Reality", International Journal of Multimedia and Recent Innovation, vol. 2, no. 1, pp. 60-75, Mar. 2020.

[13] S. N. S. Abu Samah, "The Efficacy of Augmented Reality on Student Achievement and Perception among Teluk Intan Community College Student in Learning 3D Animation", International Journal of Multimedia and Recent Innovation, vol. 2, no. 2, pp. 8795, Sep. 2020.

[14] N. Norhalim and A. Ismail, "An Early Development Process of an Augmented Reality-Based Healthy Diet Tool Prototype", International Journal of Multimedia and Recent Innovation, vol. 2, no. 2, pp. 96-101, Sep. 2020.

[15] G. Giraldi, R. L. S. Silva, P. S. Rodrigues, J. M. P. Júnior, and G. Cunha, "Augmented Reality for Engineering Applications: Dynamic Fusion of DataSets and Real World," in ISEMC International Symposium on Electromagnetic Compatibility, 2005.

[16] P. B. Davies, C. Carne, H. Mackay, and D. Tudhope, "Rapid application development (RAD): An empirical review, European Journal of Information Systems, vol. 8, no. 3, September 1999. 